CONTEMPORARY REVIEW ARTICLE

\title{
Use of Metformin in Clomiphene Citrate (CC) Resistant Polycystic Ovary Syndrome (PCOS)
}

\author{
${ }^{1}$ Mosammat Rashida Begum, ${ }^{2}$ Laila Arjumand Banu, ${ }^{3}$ Ratu Rumana Binte Rahman, ${ }^{4}$ Farhana Dewan, ${ }^{5}$ Salma Rouf \\ ${ }^{1}$ FCPS (Obstetrics and Gynecology) Dhaka Medical College \\ ${ }^{2}$ FCPS (Obstetrics and Gynecology) BIRDEM \\ ${ }^{3}$ FCPS (Obstetrics and Gynecology) SSMC \\ ${ }^{4}$ FCPS (Obstetrics and Gynecology) Dhaka Medical College \\ ${ }^{5}$ FCPS (Obstetrics and Gynecology) Dhaka Medical College
}

Correspondence: Mosammat Rashida Begum (FCPS)

e-mail: rashida_icrc@yahoo.com

\begin{abstract}
Polycystic ovary syndrome (PCOS) is a common endocrine disorder affecting between $4 \%$ and $8 \%$ of reproductive aged women. Although the symptoms and signs of PCOS are very heterogeneous, the syndrome usually presents with any combination of the following, menstrual irregularities (usually oligomenorrhea or amenorrhea), signs of hyperandrogenism (hirsutism, acne, alopecia) a characteristic appearance of the ovaries on ultrasound examination and an endocrine disturbance often involving high serum concentrations of LH and androgens.

There is a well established association between PCOS, insulin resistance and hyperinsulinemia. Insulin resistance is a pivotal defect in PCOS probably counts as one of the most important advances in the battle to control the disorder. This metabolic abnormality leads to a compensatory increase in circulating insulin and this elevated insulin level directly stimulates the ovary to produce excess androgens. It also decreases hepatic sex hormone binding globulin (SHBG), so increasing biologically available free testosterone concentration in the circulation. This metabolic derangement leads to oligomenorrhea and anovulation.

Different insulin sensitizers are used to revert the hyperinsulinemic condition. Metformin is top of them, which proved to enhance ovulation in insulin resistant PCOS when used with different ovulation inducing agents. Metformin reduces insulin resistance of peripheral tissue and allows muscle and adipose cells to take in glucose at normal insulin levels. It inhibits hepatic glucose production, decreases intestinal absorption and promotes glucose uptake, utilization by peripheral tissues at the postreceptor level. In this way it reduces insulin level and subsequently androgen level. It is easily available, safe and no teratogenic or adverse fetal outcome were reported by any researcher. It can be used safely in clomiphene resistant PCOS patients.
\end{abstract}

Keywords: Resistant PCOS, metformin, clomiphene citrate, anovulation, early pregnancy loss.

\section{INTRODUCTION}

Polycystic ovary syndrome (PCOS) is a common endocrine disorder affecting between 4 and $8 \%$ of reproductive aged women. ${ }^{1}$ Although the prevalence may be as high as $30 \%$ in women with secondary amenorrhea, $75 \%$ in women with oligomenorrhea and $90 \%$ in women with hirsutism. ${ }^{2}$ About $20 \%$ of couples seeking fertility treatment are anovulatory and 85$90 \%$ of those have PCOS. ${ }^{3}$ Although the symptoms and signs of PCOS are very heterogeneous, the syndrome usually presents with any combination of the following menstrual irregularities (usually oligomenorrhea or amenorrhea), signs of hyperandrogenism (hirsutism, acne, alopecia) a characteristic appearance of the ovaries on ultrasound examination and an endocrine disturbance often involving high serum concentrations of LH and androgens.

There is a well established association between PCOS, insulin resistance and hyperinsulinemia. Insulin resistance is a pivotal defect in PCOS probably counts as one of the most important advances in the battle to control the disorder. This metabolic abnormality leads to a compensatory increase in circulating insulin and this elevated insulin level directly stimulates the ovary to produce excess androgens. ${ }^{4,5}$ It also decreases hepatic sex hormone binding globulin $(\mathrm{SHBG}),{ }^{6}$ so increasing biologically available free testosterone concentration in the circulation. ${ }^{7,8}$

This metabolic derangement leads to oligomenorrhea and anovulation. The antiestrogen clomiphene citrate (CC) is widely accepted a first line drug for ovulation induction in PCOS. Almost $50-80 \%$ of anovulatory patients ovulate and $40-50 \%$ conceive on CC at dose of 50-150 mg/day. ${ }^{9}{ }^{10}$ However, in spite of administering high doses of CC, some patients may fail to ovulate, thus they are considered as CC resistant. The recommended maximum dose is $150 \mathrm{mg} /$ day as there is no clear evidence of efficacy at higher doses and this is in accordance 
with FDA recommendations of $750 \mathrm{mg} /$ treatment cycle. ${ }^{11} \mathrm{CC}$ resistance is associated with insulin resistance. As insulin resistance turns out to be one of the primary cause of anovulation in PCOS, we would expect drugs that reverse insulin resistance to also relieve hyperandrogenism, restore normal mense and help eliminate the infertility associated with PCOS. At the top of that list of pharmaceutical agents is metformin, which was developed in 1957 to treat type 2 diabetes. Metformin reduces insulin resistance of peripheral tissue and allows muscle and adipose cells to take in glucose at normal insulin levels. It inhibits hepatic glucose production, ${ }^{12}$ decreases intestinal absorption and promotes glucose uptake, utilization by peripheral tissues at the post receptor level. ${ }^{13}$ Metformin increases the number of insulin receptors but not insulin concentration and therefore does not cause hypoglycemia in normoglycemic patients. The sum total of these actions is a decrease in insulin levels and as a consequence a lowering of circulating total and free androgen levels with a resulting improvement of the clinical sequel of hyperandrogenism. Once androgen falls ovarian response to $\mathrm{CC}$ or other stimulating agents increases. So by reducing insulin levels by insulin sensitizer CC resistance reverts.

\section{BASIS OF HYPERINSULINEMIA AND INSULIN RESISTANCE IN PCOS}

According to Acien and colleagues ${ }^{14}$ there are at least 3 types of disorders associated with PCOS:

1. Simple hyperinsulinemic, nonhyperandrogenic obesity.

2. Typical PCOS probably with hyperactivity of steroidogenic enzymes but without hyperinsulinemia.

3. Insulin resistant PCOS resulting from anomalies in the genes involved in the secretion and action of insulin.

Insulin resistance is defined as a state in which greater than normal amounts of insulin are required to produce a quantitatively normal response. Since an initial report in 1980 of the association between PCOS and hyperinsulinemia it has become apparent that women with PCOS are both insulin resistance and hyperinsulinemic in relation to weight matched control. ${ }^{15,16}$ Insulin resistance in PCOS is due to a post-binding defect in signaling and is associated with constitutive serine phosphorylation of the insulin receptor (IR). Hyperinsulinemia plays a role in the etiopathogenesis of hyperandrogenism in women with PCOS by increasing ovarian androgen production and decreasing the serum sex hormone binding globulin (SHBG) concentration. ${ }^{17-19}$ Hyperinsulinemia is proposed to stimulate p450c, 17-alpha activity in PCOS. ${ }^{20}$ Cytochrome p450c, 17alpha is a bifunctional enzyme that has both 17-alpha hydroxylase and 17, 20-lyase activity and is key in the biosynthesis of ovarian androgens.

Hyperinsulinemia can result from any one of or a combination of the following reasons:

a. Increased insulin production by beta cells.

b. Insulin resistance in target cells or impaired hepatic insulin clearance.

Abnormalities in insulin secretion have been reported in studies of women with PCOS with and without a family history of type 2 diabetes mellitus are partly due to increased basal insulin secretion. ${ }^{21}$ This disproportionate beta cell effect is dependant on the insulin gene and its regulatory site.

\section{RELATION BETWEEN HYPERINSULINEMIA, HYPERANDROGENISM AND ANOVULATION}

Insulin and insulin like growth factor-1 (IGF-1) receptors are found in the ovary. ${ }^{22}$ Androgen production is stimulated by insulin in ovarian theca and stromal cell cultures from hyperandogenic and normal women ${ }^{18}$ and reduction of serum androgen with short-term suppression of serum insulin with diazoxide in some patients ${ }^{5}$ indicates a role for insulin in the pathophysiology of PCOS. Plasma insulin correlates with androgen levels and hyperinsulinemia may itself induce high androgen production in both the ovary ${ }^{23,24}$ and the adrenal glands. ${ }^{25}$ In vitro studies have shown that the direct ovarian effects of insulin is to increase androgen precursors from theca cells ${ }^{26}$ and aromatization in granulose cells. ${ }^{27}$ In a study on rat it was found that rat treated with insulin follicular structure was completely damaged and stromal dominance was observed. So insulin may directly play a role in follicular arrest in addition to elevating levels of androgens in the microenvironment. Besides increasing ovarian androgen production hyperinsulinemia decreases SHBG level, which further stimulates hyperandrogenism. ${ }^{5,18,19}$ However, it is not insulin resistance but the elevation of circulating insulin that stimulates ovarian androgen production and suppress SHBG. When insulin release is inhibited by diazoxide androgen and SHBG levels returns to normal. ${ }^{5}$

Insulin is responsible for glucose uptake by cells and thereby maintains blood glucose level. In PCOS there is decreased insulin clearance. This may be directly related to hyperinsulinemia, which decreases the number of hepatic receptors for insulin or secondary to hyperandrogenecity, which also decreases hepatic insulin clearance. ${ }^{28}$ Insulin resistance can exists when cellular response does not occur following exposure to insulin. The causes for such abnormal cellular response to insulin are impaired insulin receptor binding due to receptor 
defect or autoantibodies to insulin receptor as a defect in insulin signaling which is mediated through a tyrosine kinase receptor causing activation of a number of phosphorylation-dephosphorylation steps. Due to this postreceptor signaling defect there is decreased response to insulin. As insulin cannot work properly blood glucose level raised which stimulates the beta cells of pancreas to produce more insulin until blood sugar level falls. As a result insulin level rose, which causes increased secretion of androgen both by adrenal gland and ovaries. Excess androgen itself suppresses SHBG which in turn increases the free level of androgens. Thus, a vicious cycle established and hyperandrogenemia results. This excess androgen is responsible for impaired folliculogenesis and anovulation.

\section{INSULIN SENSITIZING AGENTS TO REVERT THE SITUATION}

At least five different modalities have been used to lower insulin levels in PCOS. These include weight loss, diazoxide, metformin, thiazolidinedeones (pioglitazone, rosiglitazone, troglitazone is no longer available for use) and D-chiroinositol. Among all drugs metformin is the most comprehensively evaluated drug. Both metformin and the thiazolidinediones effect reductions in insulin levels but they do so by fundamentally different mechanism. None of the insulin sensitizing drugs have Food and Drug Administration (FDA) approval for use in PCOS. Nonetheless the scientific evidence supporting their salutary effects in PCOS is substantial and progressively mounting and their use for this purpose by clinicians is already established. Although troglitazone is effective in resulting ovulation in PCOS due to need of liver transplantation and death from hepatic failure it is withdrawn from the market. ${ }^{29}$ Much published data assessing rosiglitazone and pioglitazone and D-chiroinositol in PCOS are not available. Moreover, D-chiroinositol is not yet commercially available.

\section{Metformin}

Metformin is a biguanide antihyperglycemic that is approved for the management of type 2 diabetes mellitus. The mechanism by which metformin enhance insulin sensitivity are not fully characterized. At a molecular level, metformin may increase the activity of the enzyme adenosine monophosphate-activated protein kinase. ${ }^{30}$ Metformin appears to suppress hepatic glucose output, decreased intestinal absorption of glucose, increased insulin mediated glucose utilization in peripheral tissues and has an antilypolytic effect on fatty acid concentration reducing gluconeogenesis. ${ }^{31}$ It does not produce hypoglycemia in either normal subjects or patients with type 2 diabetes. It is rapidly absorbed from the small intestine and without metabolism largely excreted in the urine. It is available in a generic form as $500 \mathrm{mg}, 850 \mathrm{mg}$ and $1000 \mathrm{mg}$ tablets. The target dose of metformin is in the range of 1500 to $2550 \mathrm{mg} .{ }^{32}$ Metformin is given with meals to reduce the gastrointestinal side effects. The most common side effects of metformin are diarrhea, nausea, vomiting, flatulence, indigestion and abdominal discomfort. The gastrointestinal side effects may be caused by high intestinal metfromin concentration that cause build-up of lactic acid in the bowel. ${ }^{33}$ A rare problem caused by metformin is lactic acidosis, which is fatal in as many as $30-50 \%$ of cases. ${ }^{34}$ Chances of lactic acidosis is increased when patients have renal insufficiency. So it should not be prescribed if serum creatinine level is greater than $1 \mathrm{mg} / \mathrm{dl}$. Liver disease, congestive heart failure and previous history of lactic acidosis are other contraindications of metformin therapy. Metfromin should be temporarily suspended for all major surgical procedures that involve restriction of fluid intake. In $10 \%$ of cases of lactic acidosis due to metformin have occurred in patients after the intravenous administration of iodinated contrast agents. ${ }^{35}$ So most authorities recommend that metformin should be discontinued 48 hours before any radiologic procedure that involves intravenous administration of iodinated contrast material. Though some authorities believe that it is safe to give contrast media to person taking metformin as long as renal function is known to be normal. ${ }^{36}$

\section{Evidences of use of Metformin in PCOS}

Number of questions are concerned regarding the use of metformin in PCOS are: Can metformin induce ovulation in PCOS with or without insulin resistance? Can it increase sensitivity of ovaries of insulin resistant PCOS patients to other ovulation inducing agents? Can metformin reduce the chance of abortion and development of gestational diabetes mellitus in PCOS patients?

The first study was done by Velazquez et $\mathrm{al}^{37}$ to test the hypothesis that androgen reduction follows from reduction of insulin by metformin. Metformin was administered to 26 women with PCOS at a dose of $500 \mathrm{mg}$ thrice daily for 8 weeks and resulted in a significant reduction in total testosterone, free testosterone, free androgen index as well as a significant rise in SHBG in comparison with pretreatment levels. Subjects of this study lost weight, which was a likely contributor to the reduction in insulin secretion. As a result the effect of metformin upon insulin secretion could not be clearly separated from that of weight loss.

To isolate the confounding effects of weight reduction on both insulin secretion and androgen levels Ehrmann D et al ${ }^{38}$ treated 14 obese non diabetic PCOS women with metformin 
for a 3 months period during which body weight was maintained and compared their ability to respond to oral and intravenous glucose challenges before and after treatment. They found that both the glucose and insulin response to a oral glucose challenge and the profound insulin resistance of obese women with PCSO were not improved by metformin. These findings were in contrast to those of Nestler and Jakubowice ${ }^{20}$ who found in a study of similar design that the area under the serum insulin curve decreased by $53 \%$ after oral glucose administration and was associated with a reduction in both the basal and luprolide stimulated serum 17-hydroxyprogesterone concentration.

Acbay and Gundogdu ${ }^{39}$ reported that insulin resistance and associated metabolic and hormonal abnormalities did not improve in patients with PCOS who were given metformin for 10 weeks. BMI did not change during the therapy so these patients did not have the beneficial effect of weight loss. However, some studies showed good results with metformin therapy in women with PCOS. One randomized placebo controlled trial showed that metformin therapy administered for 4-8 weeks resulted in decreased levels of insulin, 17-OHP and free testosterone levels and increased SHBG levels without changing in $\mathrm{BMI}^{20}$ In another placebo controlled study metformin improved hyperinsulinemia and reduced androgen levels in non obese women with PCOS within 4-6 weeks. ${ }^{40}$ No changes were noted in control group. Improvement in ovulatory rate with metformin have been reported by different authors. $^{41-44}$ On the contrary another study with 12 weeks metformin therapy did not found any improvement of adrenal androgen secretion, menstrual cyclicity and hirsutism. ${ }^{45}$ In other 8 trials on no obese PCOS metformin decreased BMI in 4 and did not reduce in 3 trials. The positive result in reducing androgen level in both the cases indicates that metformin not only acts through weight loss but also stimulates resolution of the symptoms by itself. Why metformin is successful in some studies and not in others is a concern, however, obesity, variation in the dose, genetic background and duration of therapy may be major factors in patient response.

\section{Metformin versus Clomiphene Citrate for Induction of Ovulation}

Metformin is not an ovulation inducing drug. It is a drug that effects metabolism and acts indirectly to cause ovulation by reducing the circulating concentration of insulin. On the other hand $\mathrm{CC}$ is specifically a fertility drug that acts directly to induce ovulation by blocking negative feedback on the hypothalamic pituitary axis. To compare the effects of two drugs in ovulation a head to head trial of metformin and $\mathrm{CC}$ is required. But no such study has been reported to evaluate the effects of metformin in PCOS in comparison to CC. In a multicenter study by Nestler et al ovulation rate by metformin was $34 \%$ and by CC was $8 \%$ approved metformin treatment to be more efficacious. ${ }^{46}$ But RS Legro et al found no superior effects over $\mathrm{CC}{ }^{47}$ A recent meta-analysis of 17 rigorously conducted studies with 1639 subjects shows improvement of menstrual cyclicity and ovulation rate with metformin. ${ }^{48} \mathrm{CC}$ is first acting drug with chance of multiple pregnancy, but metformin takes time to make the women ovulatory resulting in a singleton pregnancy. The ESHRE/ASRM consensus group recommended to use metformin for those patients who are not in a hurry for pregnancy and to use first acting $\mathrm{CC}$ to those who desire pregnancy immediately and for them time is of the essence. ${ }^{49}$

\section{Addition of Metformin to Clomiphene Citrate for Ovulation Induction}

Metformin has been used as an adjuvant agent for ovulation induction in women with PCOS. When metformin used alone $40 \%$ patients resumed regular cycles and ovulation ${ }^{50}$ and addition of $\mathrm{CC}$ in no responders increased ovulation rate to $67 \%$. In another study $28.2 \%$ ovulation rate and $4.2 \%$ pregnancy rate were achieved with CC in PCOS. ${ }^{51}$ But when metformin was added both ovulation and pregnancy rates were increased to $57.9 \%$ and $65.2 \%$ respectively. The combination of metformin and CC seems to be synergistic. But the ESHERE/ ASRM consensus report states that addition of metformin to $\mathrm{CC}$ as primary therapy for induction of ovulation has no beneficial effect. ${ }^{49}$ On the other hand meta-analysis conducted after the consensus paper, which includes the studies cited in the consensus paper as well as the well-designed studies reported that these addition of metformin to CC significantly increased both the ovulation rate and pregnancy rate in women with PCOS. Another positive effect of adding metformin is reduced multiple pregnancy rates.

\section{Pretreatment with Metformin before Ovulation Induction with Clomiphene Citrate}

For women who have no immediate desire for pregnancy consideration should be given to pretreatment with metformin before adding clomiphene as appropriate. ${ }^{46}$ This approach offers two advantages. Firstly, pretreatment with metformin for 2 or more months may increase the ovarian sensitivity to $\mathrm{CC}$ and may be associated with higher rates of ovulation and live birth. Secondly, obese PCOS are less responsive to CC and develop many pregnancy related complications like pre-eclampsia, diabetes mellitus. ${ }^{10}$ Metformin facilitates weight loss and pretreatment for several months can reduce those 
complications. ${ }^{52-57}$ Different studies showed positive effect of pretreatment with metformin. A multicenter randomized doubleblind placebo controlled trial ${ }^{44}$ was conducted in $\mathrm{CC}$ resistant PCOS patients. Metformin $500 \mathrm{mg}$ thrice daily or placebo alone was administered for 7 weeks and then metformin or placebo was continued in the anovulatory women, while clomiphene treatment was began at $50 \mathrm{mg}$. With ovulation the dose was not changed but with anovulation it was increased by $50 \mathrm{mg}$ for the next cycle. Significant improvements in ovulation and pregnancy rates were observed in the women treated with metformin. In the metformin group $75 \%$ ovulated in comparison to $27 \%$ in placebo group. Pregnancy rate was also higher $58 \%$ in the metformin group, whereas only $13 \%$ conceived in the placebo group. Another trial ${ }^{58}$ compared metformin with placebo before induction with CC. They used $850 \mathrm{mg}$ metformin twice daily during the first cycle and then added $100 \mathrm{mg} \mathrm{CC}$ for the subsequent cycle. In addition to a significant decrease in total testosterone, $\mathrm{LH}$ level, $\mathrm{LH} / \mathrm{FSH}$ ratio, insulin resistance and mean BMI in the study group the ovulation rate was significantly higher in the study group than in the control group (77 vs 14\%). The pregnancy rate did not differ significantly but the total number of pregnancies in the metformin group was significantly higher.

\section{Metformin as Adjuvant to Gonadotropin Ovulation Induction in CC Resistant PCOS}

Much randomized, double blind, placebo controlled trial of an insulin sensitizing drug as an adjuvant to gonadotropin ovulation induction has not yet been reported. One study evaluated the effects of metformin along with FSH in CC resistant PCOS patients. They randomized the patients to receive either no treatment or metformin $1500 \mathrm{mg}$ daily for one month prior to ovulation induction. ${ }^{59}$ Number of follicles $>15 \mathrm{~mm}$ on the day of hCG administration was significantly lower in women treated with metformin compared with untreated group (mean 2.5 vs 4.5 follicles respectively). Due to over stimulation hCG was not withheld in any cycle in women treated with metformin compared with 6 cycles withheld in untreated group. Yarali and colleagues ${ }^{60}$ did not observe any improvement in either insulin sensitivity or ovarian response in CC resistant PCOS patients when pretreated with metformin $850 \mathrm{mg}$ twice daily and then induced with recombinant FSH. Although insulin sensitivity did not change during 6 week metformin treatment an increase in spontaneous ovulation rate was observed. ${ }^{61}$ Overall ovulation rates and pregnancy rates were higher in the metformin group (94 vs $75 \%$ and 31.3 vs $6.3 \%$ ). This study showed that metformin administration during ovarian stimulation led to higher overall ovulation and pregnancy rates when given to $\mathrm{CC}$ resistant PCOS. But other authors have not observed beneficial effects of the drug despite a treatment period of $10-12$ weeks. ${ }^{38,39,60}$

\section{Metformin for In Vitro Fertilization in PCOS}

An abstract of ASRM in 1990 showed that metformin treatment increased the number of mature oocytes retrieved from women with PCOS undergoing gonadotropin stimulated in vitro fertilization (IVF) and intracytoplasmic sperm injection (ICSI). ${ }^{62}$ Metformin treatment $500 \mathrm{mg}$ twice daily from day 1 of the cycle prior to GnRH suppression significantly increased the number of mature oocytes, fertilization rates and number of embryo produced. Stadtmauer and coworker ${ }^{62}$ reported improvement in IVF and pregnancy rates in CC-resistant PCOS patients pretreated with metformin. They administered 1000$1500 \mathrm{mg}$ metformin daily for 1 cycle before induction with gonadotropins. Fertilization and clinical pregnancy rates were higher in patients who received metformin. The author observed better response when metformin was used in combination with rFSH. These studies supports the use of metformin as an adjuvant treatment in $\mathrm{CC}$ resistant PCOS.

\section{Metformin and Early Pregnancy Loss in PCOS}

Women with PCOS are at increased risk of first trimester abortion due to high LH. First trimester abortion are reported to be $30-50 \%$ in women with PCOS, ${ }^{63-67}$ which is three-fold higher than the rate of 10-15\% reported for normal women. ${ }^{68,69}$ In other way $36-82 \%$ of women with recurrent early pregnancy loss are reported to have PCOS. ${ }^{66,69-71}$ Hyperinsulinemia has been implicated as an independent risk factor for early pregnancy loss. ${ }^{72}$ Glueck et al found a very low rate of first trimester spontaneous abortion in patients receiving metformin during pregnancy. ${ }^{73}$ Metformin reduces plasminogen activator inhibitor (PAI). PAI has a positive association with worse pregnancy outcome. $^{74}$

\section{Metformin and Prevention of Gestational Diabetes Mellitus in PCOS}

Obesity, hyperinsulinema and insulin resistance of PCOS are risk factors for developing gestational diabetes. ${ }^{2,4,37,41-43,46,74-81}$ When metformin is used in resistant PCOS as adjuvant of ovulation inducing agent it reduces blood glucose level, so there is less chance of pancreatic beta cell exhaustion and development of gestational diabetes mellitus (GDM). Glueck et al found GDM in $31 \%$ of patients who did not take metformin vs $3 \%$ of patients who took it. ${ }^{82}$ It represents a 10 -fold reduction of GDM in PCOS patients who took 
metformin compared with women who did not take it. In another study Glueck et al found GDM in $7 \%$ and $30 \%$ of patients with and without metformin respectively. ${ }^{83}$ Begum MR et al ${ }^{84}$ found that GDM was higher in CC resistant PCOS patients who did not continue metformin throughout pregnancy compared with patients of same category who continued it (30 vs $3.44 \%$ ). Pregnancy increases requirements for insulin secretion. This along with insulin resistance increases demand on pancreatic beta cells. ${ }^{85-92}$ Metformin reduces the demand on pancreatic beta cells and effects maintained throughout pregnancy and may have contributed to reduce the development of GDM.

\section{SAFETY ISSUE}

Metformin for several reasons is the currently preferred insulinsensitizing drug for the treatment of infertility in PCOS. The majority of ovulation studies were conducted with metformin so the weight of scientific evidence is greater for that drug. In addition metformin is easily available worldwide with well delineated side effects and toxicities. Among commercially available insulin sensitizing drugs only metformin has a reassuring safety profile for use during pregnancy. Metformin is classified as a category B drug, which means that no teratogenic effects have been demonstrated in animal models. No teratogenic effects or adverse foetal outcome were reported by any author. ${ }^{82-84,93-95}$

\section{CONCLUSION}

Superiority to reduce hyperinsulinemia in PCOS, hence enhancing ovulation and safety of metformin was proved by many researchers. Metformin can be used safely in PCOS patients who are not responsive to CC. It can eliminate laparoscopic ovarian drilling which is invasive and risky procedure. Its adjuvant use may reduce the cost of gonadotropins and risk of multiple pregnancies. Thus, before going for laparoscopic ovarian drilling and FSH administration in CC resistant PCOS patients it is a better recommended option of treatment.

\section{RECOMMENDATIONS}

- In women with PCOS for whom pregnancy is a goal at a more distant time and patients are young then initial treatment with metformin combined with diet and exercise is an option to induce ovulation.

- In women with PCOS where rapid result is desired and patients are relatively elder with long infertility clomiphene citrate should be the first line agent.
- If patient is not responsive to $\mathrm{CC}$ or $\mathrm{CC}$ resistant then metformin can be used 6-8 weeks prior to readministration of $\mathrm{CC}$ and continued till pregnancy. Metformin can be started along with CC stimulation where previous response was nearly ovulatory.

- In spite of addition of maximum dose of metformin and CC if patient does not ovulate FSH is to be added according to response of previous cycle. This combination therapy reduces the dose of FSH and chance of hyperstimulation.

\section{REFERENCES}

1. Chang R. A practical approach to the diagnosis of polycystic ovary syndrome. Am J Obstet Gynaecol 2004;191;713-17.

2. Adams J, Polson DW, Franks S. Prevalence of polycystic ovaries in women with anovulation and idiopathic hirsutism. Br Med J 1986;293:355-59.

3. Pincock S. More data still needed on efficacy, safety of metformin for PCOS. Reuters Health Information 2002. Medscape Ob/Gyn and Women's Health 7 (2),2002.

4. Nestler JE, Jakubowicz DJ. Decreases in ovarian cytochrome P450c17 alpha activity and serum- free testosterone after reduction of insulin secretion in polycystic ovary syndrome. $\mathrm{N}$ Engl J Med 1996;335:617-23.

5. Nestler JE, Barlascini CO, Matt DW, et al. Suppression of serum insulin by diazoxide reduces serum testosterone levels in obese women with polycystic ovary syndrome. J Clin Endocrinol Metab 1989;68:1027-32.

6. Poretsky L, Cataldo NA, Rosenwaks Z, Giudice LA. The insulinrelated ovarian regulatory system in health and disease. Endocr Rev 1999;20:535-82.

7. Tsilchorozidou T, Overton C, Conway GS. The pathophysiology of polycystic ovary syndrome. Clin Endocrinol (Oxf) 2004;60: $1-17$.

8. Carmina E. Diagnosing PCOS in women who menstruate regularly. Contemp Obstet Gynaecol 2003;53-64.

9. Shepard MK, Balmaceda JP, Leija CG. Relationship of weight to successful induction of ovulation with clomiphene citrate. Fertil Steril 1979;32:641-45.

10. Lobo RA, Gysler M, March CM, et al. Clinical and laboratory predictors of clomiphene response. Fertil Steril 1982;37: 168-74.

11. Dickey RP, Taylor SN, Curole DN, Rye PH, Pyrzak R. Incidence of spontaneous abortion in clomiphene pregnancies. Hum Reprod 1996;11:2623-28.

12. Inzucchi SE, Maggs DG, Spollett GR, et al. Efficacy and metabolic effects of metformin and troglitazone in type II diabetes mellitus. N Engl J Med 1998;338:867-72.

13. Bailey CJ, Puah JA. Effect of metformin and glucose metabolism in mouse soleus muscle. Diabetes Metab 1986;12:212-18.

14. Acien P, Quereda F, Matallin P, et al. Insulin, androgens and obesity in women with and without polycystic ovary syndrome: A heterogenous group of disorders. Fertil Steril 1999;72: $32-40$. 
15. Nelson VL, Legro RS, Strauss F III, Mc Allister JM. Augmented androgen production is a stable steroidogenic phenotype of propagated theca cells from polycystic ovaries. Mol Endocrinol 1999;13:946-57.

16. Conway GS, Clark PM, Wong D. Hyperinsulinemia in the polycystic ovary syndrome confirmed with a specific immunoradiometric assay for insulin. Clinical Endocrinolgy (Oxford) 1993;38:219-22.

17. Nestler JE. Role of obesity and insulin in the development of anovulation. In: Filicori M, Flamigni C, (Eds). Ovulation induction: Basic science and clinical advances. Amsterdam: Elsevier Science BV 1994;103-14.

18. Barbieri RL, Makris A, Randwall RW, Daniels G, Kistner RW, Ryan KJ. Insulin stimulates androgen accumulation in incubations of ovarian stroma obtained from women with hyperandrogenism. J Clin Endocrinol Metab 1986;62:904-10.

19. Nestler JE, Powers LP, Matt DW, et al. A direct effect of hyperinsulinemia on serum sex hormone binding globulin levels in obese women with polycystic ovarian syndrome. J Clin Endocrinol Metab 1991;72:83-89.

20. Nestler JE, Jakubowicz DJ. Decrease in ovarian cytochrome P450c 17 alpha activity and serum free testosterone after reduction of insulin secretion in polycystic ovary syndrome. $\mathrm{N}$ Engl J Med 1996;335:617-23.

21. O'Meara NM, Blackman JD, Ehrmann DA, et al. Defects in $\beta$ cell function in functional ovarian hyperandrogenism. J Clin Endrocrinol Metab. 1993;76:1241-47.

22. Poretsky L, Grigorescu F, Seibel M, et al. Distribution and characterisation of insulin and insulin-like growth factor-1 receptors in normal human ovary. J Clin Endocrinol Metab 1985;61:728-34.

23. Stuart CA, Peters EJ, Prince MJ, et al. Insulin resistance with Acanthosis nigricans: The role of obesity and androgen excess. Metabolism 1986;35:197-205.

24. Dunaif A, Segal KR, Shelley DR, et al. Evidence for distinctive and intrinsic defects in insulin action in polycystic ovary syndrome. Diabetes. 1992;41:1257-66.

25. Moghetti P, Castello R, Negri C, et al. Insulin infusion amplifies 17 alpha hydroxycorticosteroid intermediates response to adrenocorticotropin in hyperandrogenic women: Apparent relative impairment of 17, 20-lyase activity. J Clin Endocrinol Metab 1996;81:881-86.

26. Willis D, Manson H, Gilling Smith C, et al. Modulation by insulin of follicle stimulating hormone and luteinizing hormone actions in human granulose cells of normal and polycystic ovaries. J Clin Endocrinol Metab. 1996;81:302-09.

27. McAllister JM, Byrd W, Simpson ER. The effects of growth factors and phorbol esters on steroid biosynthesis in isolated human theca interna and granulose-lutein cells in long-term culture. J Clin Endocrinol Metab 1994;79:106-12.

28. Peiris AN, Mueller RA, Struve MF, Smith GA, Kissrbah AH. Relationship of androgenic activity to splanchnic insulin metabolism and peripheral glucose utilization in premenopausal women. J Clin Endocrinol Metab 1987;64:162-69.

29. Perloe M. Polycystic ovary syndrome: Treatment with insulin lowering medications. www ivf.com.
30. Zhou G, Myers R, Li Y, Shen X, Fenyk-Melody J, et al. Role of AMP-activated protein kinase in mechanism of metformin action. J Clin Invest. 2001;108:1167-74.

31. Bailey CJ, Turner RC. Metformin. N Eng J Med 1996;334:57479.

32. Patance G, Piro S, Rabuazzo AM, Anello M, Vigneri R, Purrello F. Metformin restores insulin secretion altered by chronic exposure to free fatty acids or high glucose: A direct metformin effect on pancreatic beta cells. Diabetes 2000;49:735-40.

33. Wilcock C, Bailey CJ. Accumulation of metformin by tissues of the normal and diabetic mouse. Xenobiotica 1994;24:49-57.

34. Lalau JD, Lacroix C, Compagnon P, de Cagny B, Rigaud JP, Bleichner $\mathrm{G}$, et al. Role of metformin accumulation in metformin associated lactic acidosis. Diabetes Care 1995;18:779-84.

35. Moros SK, Thomsen HS. Adverse reactions to iodinated contrast media. Eur Radiol 2001;11:1267-75.

36. McCartney MM, Gilbert FJ, Murchison LE, Pearson D, Mchardy $\mathrm{K}$, Murray AD. Metformin and contrast media-a dangerous combination. Clin Radiol 1999;54:29-33.

37. Velazquez EM, Mendoza SG, Wang P, Glueck CJ. Metformin therapy is associated with a decrease in plasma plasminogen activator inhibitor -1 , lipoprotein (a) and immunoreactive insulin levels in patients with the polycystic ovary syndrome. Metabolism 1997;46:454-57.

38. Ehrmann D, Cavaghan M, Imperial J, Sturis J, Rosenfield R, Polonsky K. Effects of metformin on insulin secretion, insulin action and ovarian steroidogenesis in women with polycystic ovary syndrome. J Clin Endocrinol Metab 1997;82:524-30.

39. Acbay O, Gundogdu S. Can metformin reduce insulin resistance in polycystic ovary syndrome Ferti Steril 1996;65:946-49.

40. Nestler JE, Jakubowicz DJ. Lean women with polycystic ovary syndrome respond to insulin reduction with decrease in ovarian P450c 17 alpha activity and serum androgens. J Clin Endocrinol Metab 1997;82:4075-79.

41. Velazquez ME, Acosta A, Mendoza SG. Menstrual cyclicity alter metformin therapy in polycystic ovary syndrome. Obstet Gynaecol 1997;90:392-95.

42. Glueck CJ, Wang P, Fontaine R, et al. Metformin induced resumption of normal menses in 39 of $43(91 \%)$ previously amenorrheic women with polycystic ovary syndrome. Metabolism 1999;48:511-19.

43. Moghetti P, Casello R, Negri C, et al. Metformin effects on clinical features, endocrine and metabolic profiles and insulin sensitivity in polycystic ovary syndrome: A randomized doubleblind, placebo controlled 6 month trial, followed by open longterm clinical evaluation. J Clin Endocrinol Metab 2000;85: 139-46.

44. Vandermolen DT, Ratts VS, Evans WS, et al. Metfrormin inceases the ovulatory rate and pregnancy rate from clomiphene citrate in patients with polycystic ovary syndrome who are resistant to clomiphene citrate alone. Fertil Steril 2001;75: 310-15.

45. Unluhizarci K, Kelestimur F, Sahin Y, Bayram F. The treatment of insulin resistance does not improve adrenal cytochrome p450c 17 alpha enzyme dysregulation in polycystic ovary syndrome. Eur J Endocrinol 1990;140:56-61. 
46. Nestler JE, Jakubowicz DJ, Evans WS, Pasquali R. Effects of metformin on spontaneous and clomiphene-induced ovulation in the polycystic ovary syndrome. N Eng J Med 1998;338:187680.

47. Legro RS, Barnhart HX, Schlaff WD, Carr BR, Diamond MP, Carson SA et al. Clomiphene, metformin or both for infertility in the polycystic ovary syndrome. N Engl J Med 2007;356:55166.

48. Creanga AA, Bradley HM, McCormick C, Witkop CT. Use of metformin in polycystic ovary syndrome: A meta-analysis. Obstet Gynaecol 2008;111:959-68.

49. Thessaloniki ESHRE/ASRM-Sponsored PCOS Consensus Workshop Group. Consensus on infertility treatment related to polycystic ovary syndrome. Fertil Steril 2008;89:505-22.

50. Heard MJ, Pierce A, Carson SA, Buster JE. Pregnancies following use of metformin for ovulation induction in patients with polycystic ovary syndrome. Fertil Steril 2002;77:669-73.

51. Batukan C, Baysal B. Metformin improves ovulation and pregnancy rates in patients with polycystic ovary syndrome. Arch Gynecol Obstet 2001;265:124-27.

52. Dunaif A. Drug insight: Insulin sensitizing drugs in the treatment of polycystic ovary syndrome - a reappraisal. Nat Clin Pract Endocrinol Metab. 2008;4:272-83.

53. Golay A. Metformin and body weight. Int J Obes (London). 2008;32:61-72.

54. Harbone LR, Sattar N, Norman JE, Fleming R. Metformin and weight loss in obese with polycystic ovary syndrome: Comparison of doses. J Clin Endocrinol Metab 2005;90:459398.

55. Pasquali R, Gambineri A, Biscotti, Vicennati V, Gagliardi L, Colitta D, et al. Effect of long-term treatment with metformin added to hypocaloric diet on body composition, fat distribution, and androgen and insulin levels in abdominally obese women with and without the polycystic ovary syndrome. J Clin Endocrinol Metab 2000;85:2767-74.

56. Gambineri A, Pelusi C, Genghini S, Morselli-Labate AM, Cacciari M, Pagotto U, et al. Effect of flutamide and metformin administered alone or in combination in dieting obese women with polycystic ovary syndrome. Clin Endocrinol (Oxf) 2004;60:241-49.

57. Barbieri RL. Clomiphene versus metformin for ovulation induction in polycystic ovary syndrome: the winner is... J Clin Endocrinol Metab 2007;92:3399-3401.

58. Kocak M, Caliskan E, Simsir C, Haberal A. Metformin therapy improves ovulatory rates, cervical scores, and pregnancy rates in clomiphene citrate resistant women with polycystic ovary syndrome. Fertil Steril 2002;77:101-06.

59. De Leo V, la Marca A, Ditto A, Morgante G, Cianci A. Effects of metformin on gonadotropin-induced ovulation in women with polycystic ovary syndrome. Fertil Steril 1999;72:S12.

60. Yarali H, Yildiz BO, Demirol A, et al. Co-administration of metformin during rFSH treatment in patients with clomiphene citrate resistant polycystic ovarian syndrome: A prospective randomized trial. Hum Reprod 2002;17:289-94.

61. Duleba AJ, Pawelczyk LA, Ho Yuen B, et al. Insulin action on ovarian steroidogenesis are not modulated by metformin. Hum Reprod. 1993;8:1194-98.
62. Stadtmauer LA, Toma SK, Riehl RM, Talbert LM. Metformin treatment of patients with polycystic ovary syndrome undergoing in vitro fertilization improves outcomes and is associated with modulation of the insulin-like growth factors. Fertil Steril 2001;75:505-09.

63. Balen AH, Tan SL, MacDougall J, Jacobs HS. Miscarriage rates following in vitro fertilization are increased in women with polycystic ovaries and reduced by pituitary desensitization with buserelin. Hum Reprod 1993;8:959-64.

64. Homburg R, Armar NA, Eshel A, Adams J, Jacobs HS. Influence of serum Leutenizing become concentration on ovulation, conception, and early pregnancy loss in polycystic ovary syndrome. BMJ 1988;297:1024-26.

65. Regan L, Owen EJ, Jacobs HS. Hypersecretion of Leutenizing hormone, infertility, and miscarriage. Lancet 1990;336:114144.

66. Sagle M, Bishop K, Ridley N, Alexander FM, Michel M, Bonney $\mathrm{RC}$, et al. Recurrent early miscarriage and polycystic ovaries. BMJ 1988;297:1027-28.

67. Watson H, Kiddy DS, Hamilton-Fairley D, Scanlon MJ, Barnard C, Collins WP, et al. Hypersecretion of luteinizing hormone and ovarian steroids in women with recurrent early miscarriage. Hum Reprod 1993;8:829-33.

68. Gray RH, Wu LY. Subfertility and risk of spontaneous abortion. Am J Public Health 2000;90:1452-54.

69. Regan L, Braude PR, Trembath PL. Influence of past reproductive performance on risk of spontaneous abortion. BMJ 1989;299:541-45.

70. Clifford K, Rai R, Watson H, Regan L. An informative protocol for the investigation of recurrent miscarriage: Preliminary experience of 500 consecutive cases. Hum Reprod 1994;9: 1328-32.

71. Liddell HS, Sowden K, Farquhar CM. Recurrent miscarriage: Screening for polycystic ovaries and subsequent pregnancy outcome. Aust N Z J Obstet Gynaecol 1997;37:402-06.

72. Fedorcsak P, Storeng R, Dale PO, Tanbo T, Abyholm T. Obesity is a risk factor for early pregnancy loss ater IVF or ICSI. Acta Obstet Gynaecol Scand 2000;79:43-48.

73. Glueck CJ, Cameron D, Sieve-Smith BA, Wang P. Continuing metformin throughout pregnancy in women with polycystic ovary syndrome appears to safely reduce first-trimester spontaneous abortion: A pilot study. Fertil Steril 2002;77: 520-25.

74. Glueck CJ, Wang P, Fontaine RN, Sieve-Smith L, Tracy T, Moore SK. Plasminogen activator inhibitor activity (an independent risk factor for the high miscarriage rate during pregnancy in women with polycystic ovary syndrome). Metabolism 1999;48:1589-95.

75. Diamanti-Kandarakis E, Kouli C, Tsianateli T, Bergiele A. Therapeutic effects of metformin on insulin resistance and hyperandrogenism in polycystic ovary syndrome. Eur J Endocrinol 1998;138:269-74.

76. Morin-Papunen LC, Koivunen RM, Ruokonen A, Martikainen HK. Metformin therapy improves the menstrual pattern with minimal endocrine and metabolic effects in women with polycystic ovary syndrome. Fertil Steril 1998;69:691-96. 
77. Velazquez EM, Mendoza SG, Hamer T, Sosa F, Glueck CJ. Metformin therapy in polycystic ovary syndrome reduces hyperinsulinemia, insulin resistance, hyperandrogenimia, and systolic blood pressure, while facilitating normal menses and pregnancy. Metabolism 1994;43:647-54.

78. Glueck CJ, Phillips H, Cameron D, Sieve-Smith L, Wang P. Continuing metformin throughout pregnancy in women with polycystic ovary syndrome appears to safely reduce firsttrimester spontaneous abortion (a pilot study). Fertil Steril 2001;75:46-52.

79. Zawadzki JK, Dunaif A. Diagnostic criteria for polycystic ovary syndrome (a rational approach). In: Dunaif A, Givens JR, Haseltine F, Merriam GR editor. Polycystic ovary syndrome. Cambridge, MA: Blackwell Scientific; 1992;377-84.

80. Lobo RA, Carmina E. The importance of diagnosing the polycystic ovary syndrome. Ann Intern Med 2000;132:989-93.

81. Mikola M, Hiilesmaa V, Hailttunen M, Suhonen L, Tiitinen A. Obstetric outcome in women with polycystic ovarian syndrome. Hum Reprod 2001;16:226-29.

82. Glueck CJ, Wang P, Kobayashi S, Phillips H, Sieve-Smith L. Metformin therapy throughout pregnancy reduces the development of gestational diabetes in women with polycystic ovary syndrome. Fertil Steril. 2002;77:520-25.

83. Charles J Glueck, Joel Pranik off, Dawit Aregawi, Ping Wang. Prevention of gestational diabetes by metformin plus diet in patients with polycystic ovary syndrome. Fertil Steril 2008;89:625-34.

84. Begum MR, Khanam NN, Quadir E, Ferdous J, Begum MS, Khan F, Begum A. Prevention of GDM by continuing metformin therapy throughout pregnancy in women with polycystic ovary syndrome (PCOS). Journal of Obstetrical and Gynaecological Research. (In Press).

85. Anttila L, Karjala K, Penttila RA, Ruutiainen K, Ekblad U. Polycystic ovaries in women with gestational diabetes. Obstet Gynecol 1998;92:13-16.
86. Holte J, Gennarelli G, Wide L, Lithell H, Berne C. High prevalence of polycystic ovaries and associated clinical, endocrine, and metabolic features in women with previous gestational diabetes mellitus. J Clin Endocrinol Metab 1998;84:1143-50.

87. Kousta E, Cela E, Lawrence N, Penny A, Millauer B, White D, et al. The prevalence of polycystic ovaries in women with a history of gestational diabetes. Clin Endocrinol (Oxf). 2000;53:501-07.

88. Lanzone A, Caruso A, Di Simone N, De Carolis S, Fulghesu AM, Mancuso S. Polycystic ovary disease. A risk factor for gestational diabetes? J Reprod Med 1995;40:312-16.

89. Lesser KB, Garcia FA. Association between polycystic ovary syndrome and glucose intolerance during pregnancy. J Matern Fetal Med 1997;6:303-07.

90. Paradisi G, Fughesu AM, Ferrazzani S, Moretti S, Ptoro C, Soranna L, et al. Endocrinometabolic features in women with polycystic ovary syndrome during pregnancy. Hum Reprod 1998;13:542-46.

91. Radon PA, McMahon MJ, Meyer WR. Impaired glucose tolerance in pregnant women with polycystic ovary syndrome. Diabetologia 1999;94:194-97.

92. Butte NF. Carbohydrate and lipid metabolism in pregnancy (normal compared with gestational diabetes mellitus). Am J Clin Nutr. 2000;71(suppl):1256S-61S.

93. Coetzee EJ, Jackson WPU. Metformin in management of pregnant insulin-independent diabetes. Diabetologia 1979; 16:241-45.

94. Coetzee EJ, Jackson WPU. Oral hypoglycaemics in the first trimester and foetal outcome. S Afr Med J 1984;65:635-37.

95. Coetzee EJ, Jackson WPU. The management of non-insulindependent diabetes during pregnancy. Diabetes Res Clin Pract 1985;1:281-87. 